\title{
A APRENDIZAGEM BASEADA EM PROBLEMA (ABP) PARA O ENSINO DA EDUCAÇÃO AMBIENTAL NA FORMAÇÃO DE PROFESSORES DE CIÊNCIAS
}

\author{
PROBLEM-BASED LEARNING (PBL) FOR WORKING WITH \\ ENVIRONMENTAL EDUCATION IN THE SCIENCE TEACHER \\ PREPARATION
}

\section{EL APRENDIZAJE BASADO EN PROBLEMA (ABP) PARA LA ENSEÑANZA DE LA EDUCACIÓN AMBIENTAL EN LA FORMACIÓN DE PROFESORES DE CIENCIAS}

\author{
Thais Benetti de Oliveira \\ Universidade Sagrado Coração (USC), Doutora em Educação para Ciência e docente do \\ curso de Ciências Biológicas. \\ E-mail: thaisbbbp@ hotmail.com \\ Ana Maria de Andrade Caldeira \\ Universidade Estadual Paulista "Júlio de Mesquita Filho" (UNESP), Professora Adjunta \\ do Departamento de Educação da Faculdade de Ciências, Campus de Bauru. \\ E-mail: anacaldeira@fc.unesp.br
}

\section{RESUMO}

As mudanças didático - pedagógicas que circunscrevem a Educação científica contemporânea primam o uso de metodologias a partir das quais o aluno seja um sujeito ativo no processo de ensino - aprendizagem e possa, portanto, desenvolver habilidades de análise, interpretação de textos, pesquisa, levantamento de hipóteses e resolução de problemas. Dentre essas metodologias, a aprendizagem baseada em problemas (ABP) pode favorecer o trabalho com a Educação Ambiental (EA) na formação de professores de Ciências, já que contribui com a produção de conhecimentos recontextualizados às necessidades e transitoriedades dos sujeitos que enfrentam e atuam na sociedade contemporânea. A partir disso, este artigo prioriza uma discussão teórica que articulará o potencial epistemológico da Educação Ambiental para ser trabalhada, nos cursos de formação de professores, por meio da aprendizagem baseada em problema. Para tanto, contemplará dois principais objetivos: a articulação entre a Educação Ambiental e o trabalho com metodologias ativas - identificando aspectos teóricos e práticos e a exemplificação pedagógica de como essa articulação pode legitimar-se na Formação Inicial de professores de Ciências, considerando a importância de se formar professores capazes de trabalhar a EA na Educação Básica.

Palavras-chave: Formação de professores de Ciências; Educação Ambiental; Metodologias ativas.

\footnotetext{
ABSTRACT

The didactic - pedagogical changes that circumscribe contemporary scientific education prioritize the use of methodologies from which the student is an active subject in the 
teaching - learning process and can, therefore, develop analysis skills, text interpretation, research, raising hypotheses and troubleshooting. Among these methodologies, problem-based learning (PBL) can favor the work of Environmental Education (EE) in the science teacher preparation, since it contributes to the production of recontextualized knowledge to the needs and transistorizes of the subjects that face and act in the society. From this, this article prioritizes a theoretical discussion that will articulate the epistemological potential of Environmental Education to be worked out, in teacher training, through problem - based learning. To do so, it will contemplate two main objectives: the articulation between Environmental Education and the work with active methodologies - identifying theoretical and practical aspects and the pedagogical exemplification of how this articulation can legitimize itself in science teacher training, considering how important it is to train teachers to be capable of working with EE in elementary education.

Keywords: Science teacher preparation; Environmental Education; Active methodologies.

\section{RESUMEN}

Los cambios didácticos-pedagógicos que circunscriben la Educación científica contemporánea priman el uso de metodologías a partir de las cuales el alumno sea un sujeto activo en el proceso de enseñanza - aprendizaje y pueda, por lo tanto, desarrollar habilidades de análisis, interpretación de textos, investigación, levantamiento de textos hipótesis y resolución de problemas. En el caso de los profesores de ciencias, el aprendizaje basado en problemas (ABP) puede favorecer el trabajo con la Educación Ambiental (EA) en la formación de profesores de Ciencias, ya que contribuye con la producción de conocimientos recontextualizados a las necesidades y transitorias de los sujetos que enfrentan y actúan en la sociedad sociedad contemporánea. A partir de eso, este artículo prioriza una discusión teórica que articulará el potencial epistemológico de la Educación Ambiental para ser trabajada, en los cursos de formación de profesores, por medio del aprendizaje basado en problema. Para ello, contemplará dos principales objetivos: la articulación entre la Educación Ambiental y el trabajo con metodologías activas - identificando aspectos teóricos y prácticos y la ejemplificación pedagógica de cómo esa articulación puede legitimarse en la Formación Inicial de profesores de Ciencias, considerando la importancia de se forman profesores capaces de trabajar la EA en la Educación Básica.

Palabras clave: Formación de profesores de ciencias; Educación ambiental; Metodologías activas.

\section{INTRODUÇÃO}

Em uma sociedade em mudança, em construção, contraditória, com profissionais em estágios desiguais de evolução cognitiva, emocional e moral, tudo é mais complexo e difícil. Uma escola imperfeita é a expressão de uma sociedade, também, imperfeita, híbrida, contraditória (MORÁN, 2015, p.28). 
A reflexão suscitada pelo trecho acima é plausível e válida dentro dos pressupostos sobre a Educação Científica contemporânea. Se iremos discutir sobre as necessárias e imputáveis alterações e possibilidades didático-metodológicas que precisam ocorrer na Formação Inicial de professores, é preciso entendermos que os pressupostos práticos e epistemológicos que regem a prática docente estão associados a uma transitoriedade natural da sociedade em que vivemos.

Essa transitoriedade é marcada, principalmente, por temáticas recorrentes no cotidiano, vivenciadas por todos os cidadãos (dentro ou fora da escola) e que, portanto, precisam estar inseridas na formação de professores e, por conseguinte, na escola. Por exemplo, a partir da década de 1980, a questão ambiental foi incluída como eixo transversal nos currículos de Educação Básica. Passou também a ser discutida por campos de interesses distintos - político, econômico, social e cultural - enquanto na maior parte das vezes, nas escolas, fora apresentado a partir de uma lista de conceitos associados estritamente às disciplinas de Ciências, Biologia e Geografia.

Os recursos naturais e a biodiversidade vêm sendo degradados rapidamente em razão de seu uso inadequado e ostensivo, o que acarreta transformações mundiais ligadas a questões ambientais como fenômenos de aquecimento global, destruição da camada de ozônio, desmatamento, entre outros. Essa problemática ambiental engendra a necessidade de repensarmos discursos cujo conteúdo baseia-se no jargão "cuidar do meio ambiente/natureza e dos recursos para que não se esgotem" e para que "possamos desenvolver uma sociedade sustentável" (RIBEIRO; CAVASSAN, 2013, p.62) no âmbito da formação de professores. Para que esse discurso seja, de fato, assentado em significados, ações de intervenção e mudanças de atitudes é necessário que a formação inicial de professores desenvolva um trabalho específico voltado às questões ambientais a partir de metodologias e abordagens contemporâneas, as quais priorizem o envolvimento do aluno com as atividades propostas.

A partir disso, este artigo prioriza uma discussão teórica que articulará o potencial epistemológico da Educação Ambiental para ser trabalhada, nos cursos de formação de professores, por meio da aprendizagem baseada em problema.

Tendo em vista a importância da temática no contexto brasileiro, apresentar-se-á dois objetivos. O primeiro se dá na articulação entre a Educação Ambiental e o trabalho com metodologias ativas - identificando aspectos teóricos e práticos. O segundo se propõe a exemplificar, pedagogicamente, como essa articulação pode legitimar-se nos 
cursos de formação de professores de Ciências, considerando a importância de se formar professores capazes de trabalhar a EA na Educação Básica.

A aproximação entre a proposição de problemas e a EA pode permitir uma formação e atuação docente na educação científica que problematize e ressignifique a EA para além de uma lista de conceitos associados estritamente às disciplinas de Biologia e que situe a universidade como um espaço orgânico de produção de conhecimentos recontextualizados às necessidades e transitoriedades dos sujeitos que enfrentam e atuam na sociedade contemporânea.

\section{A EDUCAÇÃO AMBIENTAL NA FORMAÇÃO INICIAL}

A temática ambiental aparece na sociedade contemporânea como uma preocupação que atinge diversos segmentos sociais e figura no centro de muitos debates nacionais e internacionais. Nestes contextos, frequentemente, a educação tem sido apontada como uma das principais vias de enfrentamento dos problemas ambientais já que pode contribuir para formação de pessoas capazes de provocar mudanças significativas na situação de degradação socioambiental com a qual nos deparamos.

A Educação Ambiental (EA) surge, portanto, como uma resposta à crise ambiental e objetiva uma mudança premente nas relações entre sociedade e natureza. De acordo com a visão socioambiental, a EA procura superar dicotomia entre o ser humano e a natureza, um dos valores da modernidade. Para tanto, provê mudanças culturais, que culminariam com a formação de sujeitos com atitude ecológica, que tenham consciência sobre as relações entre sociedade e ambiente e que ajam para contribuir com a melhoria dessas relações (SOUZA; SALVI, 2012).

Pensando na organização fragmentada e estanque dos conteúdos dos cursos de Ciências Biológicas e Pedagogia, ratifica-se a potencialidade da inserção da perspectiva crítica da EA nos currículos e na cultura científica como possibilidade de formar cidadãos capazes de integrar as diferentes dimensões do conhecimento em suas múltiplas facetas de manifestação científica ou social, enxergando de forma sistêmica as problematizações contemporâneas e posicionando-se criticamente frente a elas.

A problematização desta proposta envolve a urgência de se abordar conteúdos referentes à Educação Ambiental na formação de professores de Ciências, uma vez que os problemas ambientais - muitos decorrentes de ações predatórias e indevidas do ambiente natural por parte do homem - tem afetado a vida econômica e social em âmbitos mundiais. A ideia de uma formação cidadã que contemple conteúdos atitudinais 
deve começar nas séries iniciais a partir de conteúdos que envolvam o conhecimento e a percepção do meio, de maneira que a criança se reconheça como parte desse ambiente e, portanto, desenvolva atitudes de afetividade e cuidado com o meio em que vive.

Embora a EA seja uma área bastante complexa, é preciso reconhecer que a formação voltada à cidadania, a intervenção na sociedade deve ser um eixo que compõe todos os níveis da Educação Básica como um caminho metodológico de formação cidadã e ativa do estudante. Muito do que é discutido no âmbito de formação de professores, principalmente no que tange à inserção de metodologias ou conteúdos específicos nas salas de aula, fica destituído de sentido prático, já que se discute muito sobre a prática do professor sem, no entanto, fornecer estratégias para que uma mudança efetiva ocorra no contexto da escola ou da universidade. Além disso, é preciso identificar o que, de fato, os professores que estão inseridos no cotidiano escolar precisam para realizar o que prevemos em compilações e especulações teóricas.

O consenso quanto à necessidade urgente de uma implantação da Educação Ambiental em todos os níveis de ensino é acompanhado pelo debate que circunscreve a questão de como efetivar, na prática, uma mudança dos programas educacionais. Pois, apesar do reconhecimento acerca da importância da Educação Ambiental, os professores não possuem conhecimentos necessários para integrar seus conceitos e princípios ao processo de ensino (STIR, 2006).

Não basta reproduzir discursos sobre a consciência de que o ambiente precisa ser preservado para que as pessoas adotem atitudes ambientalmente sustentáveis. Ao contrário, só a construção de um saber específico, relacionado ao meio ambiente local, poderá provocar mudanças significativas nas práticas de ensino-aprendizagem e no cotidiano das pessoas. Para tal, é necessário pensarmos em propostas metodológicas de ensino que possam tornar a Educação Ambiental formal mais atraente e contextualizada (NICOLLIER; VELASCO, 2009).

Há, por exemplo, o desejo de se efetuar uma EA articulada com o exercício da cidadania, mas muitas vezes problematizações não articuladas com problemas da realidade do aluno podem conduzir a uma aprendizagem restrita a conteúdos conceituais. Apesar da difusão crescente, a EA apresenta-se fragilizada em suas ações pedagógicas, na medida em que elas não geram transformações significativas da realidade (GUIMARÃES, 2010), tampouco tem possibilitado a ampliação da percepção 
do meio ambiente. Nesse sentido, é fundamental um aperfeiçoamento de seus procedimentos metodológicos (PEDRINI; SAITO, 2014).

A Educação Ambiental é entendida por muitos professores da Educação Básica como uma possibilidade de trabalho prático com um tema que envolva o meio ambiente. As escolas, por muitas vezes, assumem desenvolver projetos de Educação Ambiental que ficam reduzidos a um discurso de "separação de lixos". Essa falta de sentido epistemológico para caracterizar a complexidade da Educação Ambiental deve ser estudada, inicialmente, na Formação Inicial de professores: Quais disciplinas e/ou conteúdos permitem que os futuros professores de Ciências possam discutir e/ou propor projetos de cunho ambiental? Quais estratégias podem ser adotadas para que a EA seja entendida como uma área de conhecimento cujo objeto de estudo envolve múltiplas dimensões? Como se distanciar de uma concepção de Educação Ambiental restrita a sumarizações de termos científicos da Biologia e da Geografia?

Se, por um lado, as sinalizações dos Parâmetros Curriculares Nacionais, por exemplo, são compatíveis com uma ideia geral de Ensino de Ciências comprometido com uma maior permeabilidade a valores humanos e sociais, a valores éticos e à cidadania, de outro, resta o desafio de se explicitar as possibilidades cotidianas dessa ideia e, ainda, contrapô-la às necessidades programáticas de conteúdos escolares. Assim, outra questão que pode ser colocada diz respeito a: que tipo de trabalho docente e discente está implicado no desenvolvimento de visões críticas sobre a Educação Ambiental?

Os discursos em favor da formação de estudantes mais comprometidos com os valores sociais e os princípios de solidariedade não garantem intervenções efetivas no âmbito pedagógico. Muitas práticas educativas fazem uso de modelos didáticos que não alcançam o que os discursos almejam: o desenvolvimento da responsabilidade individual e coletiva, a igualdade, o respeito e o diálogo democrático (RIBEIRO; CAVASSAN, 2016).

Para que a Educação Ambiental promova mudanças efetivas no âmbito escolar, é necessário que o ambiente seja abordado a partir de conteúdos conceituais, procedimentais e atitudinais de maneira que os estudantes possam ampliar a sua percepção acerca do meio ambiente, de modo a construir novas relações significativas e ampliar a visão de mundo. Para Ribeiro e Cavassan (2016), esses componentes conceituais, procedimentais e atitudinais constituem, portanto, o que denominam de competência ambiental (Quadro 1). “Tal competência é composta por elementos já 
presentes nos discursos de EA, mas que, muitas vezes, não são considerados objetos legitimados de ensino e de aprendizagem" (RIBEIRO; CAVASSAN, 2016, p.25).

Quadro 1 - Elementos estruturantes da competência ambiental.

\begin{tabular}{|l|l|}
\hline \multicolumn{1}{|c|}{ Conteúdos } & \multicolumn{1}{|c|}{ Conhecimentos - Objetos de ensino e de aprendizagem } \\
\hline Conteúdos conceituais & $\begin{array}{l}\text { Conhecimentos curriculares do campo das Ciências Naturais e } \\
\text { Sociais. Conteúdos socialmente relevantes, selecionados de acordo } \\
\text { com suas potencialidades formativas. }\end{array}$ \\
\hline $\begin{array}{l}\text { Conteúdos } \\
\text { procedimentais }\end{array}$ & $\begin{array}{l}\text { Habilidades sociais e comunicativas que fundamentam as relações } \\
\text { interpessoais (saber dialogar, relacionar-se, conviver, partilhar } \\
\text { informações, cooperar, ouvir e reconsiderar ideias, saber respeitar e } \\
\text { valorizar a diversidade de perspectivas etc.). }\end{array}$ \\
\hline Conteúdos atitudinais & Respeito, cooperação, autonomia e democracia. \\
\hline
\end{tabular}

Fonte: Ribeiro e Cavassan (2016, p. 25).

A partir da definição de "competência ambiental" proposta, é necessário pensarmos que, para que esse discurso seja, de fato, carregado de significados, ações de intervenção e/ou mudanças de atitudes deve atingir os espaços de Formação Inicial de professores tanto no que tange a dimensão pedagógica (quais as práticas docentes envolvem ações voltadas à preservação ambiental?); quanto à dimensão de conteúdos (quais atitudes, conceitos e procedimentos podem ser trabalhados nas escolas voltadas ao conhecimento e ao cuidado com os problemas ambientais de modo a proporcionar ações efetivas de intervenção?) e de objetivos de aprendizagem (o que, em âmbito de planejamento, é construído para a discussão e/ou ensino de habilidades relacionadas ao ambiente?).

Embora o trabalho com atitudes seja relevante, não podemos supor que os discursos e pesquisas sobre formação para cidadania proporcionem, concomitantemente, mudanças significativas nas práticas docentes. Os discursos em favor da formação de estudantes mais comprometidos com os valores sociais e os princípios de solidariedade não garantem intervenções efetivas no âmbito pedagógico. Muitas práticas educativas fazem uso de modelos didáticos que não alcançam o que os discursos almejam: o desenvolvimento da responsabilidade individual e coletiva, a igualdade, o respeito e o diálogo democrático (RIBEIRO; CAVASSAN, 2016).

Além disso, apontamos ausência de estratégias metodológicas que efetivamente possam ser aplicadas pelos professores da Educação Básica como uma iniciativa ou proposta de trabalho com a Educação Ambiental. O distanciamento entre a academia e a 
escola (entre professores e pesquisadores) configura um descompasso entre os resultados das pesquisas e a prática do professor, dificultando que as práticas pedagógicas sejam inovadoras, balizadas em referenciais teóricos sólidos e atuais (DELIZOICOV; ANGOTTI; PERNAMBUCO, 2011).

É com essa lógica que, cabe às universidades e as instituições de pesquisa, o papel de investigar e desenvolver um quadro teórico e material que dê suporte ao trabalho nas escolas. Principalmente em temas como a Educação Ambiental, seja contribuindo diretamente com sua aplicação - o que corresponderia aos trabalhos do foco temático analisado, ao avaliarem estratégias de ensino - seja na formação de professores nos quadros ligados ao sistema escolar (KRASILCHIK, 1987).

Por exemplo, as pesquisas empíricas que objetivam a conservação de determinadas espécies locais são destinadas ao entendimento apenas de um grupo inserido em uma "expertise" específica, que, então, irá mobilizar-se para propor e desenvolver estratégias voltadas à preservação.

Isto posto, consideramos necessário o estudo de metodologias que favoreçam, dentro da EA, o trabalho com conceitos, procedimentos e atitudes e o desenvolvimento da competência ambiental por meio de um envolvimento genuíno do estudante com a situação de aprendizagem e a realidade, o que pode ser fomentado pela aprendizagem baseada em problema.

\section{EDUCAÇÃO AMBIENTAL E A APRENDIZAGEM BASEADA EM PROBLEMAS: UMA POSSIBILIDADE METODOLÓGICA}

A Aprendizagem Baseada em Problemas é um método de aprendizagem que, nos últimos anos, tem conquistado espaço em inúmeras instituições educacionais de ensino superior (nos cursos de graduação e pós-graduação) e no ensino básico em diversas disciplinas (SOUZA; DOURADO, 2015).

A ABP como uma estratégia de método para aprendizagem, centrada no aluno e por meio da investigação, tendo em vista à produção de conhecimento individual e grupal, de forma cooperativa, e que utiliza técnicas de análise crítica, para a compreensão e resolução de problemas de forma significativa e em interação contínua com o professor tutor (SOUZA; DOURADO, 2015, p. 184).

Vasconcellos, Berbel e Oliveira (2011) argumentam que a metodologia da problematização é uma alternativa de contribuição efetiva para formar o professorpesquisador, já que se apresenta com potencial promissor para o ensino e para a 
pesquisa, constituindo uma referência para a docência no ensino superior, para a área de didática e para os pesquisadores, em sua formação continuada. Reverberam sobre a necessidade de se continuar a insistir no envolvimento dos alunos de graduação/futuros professores em um ensino com pesquisa, dando oportunidades para que eles desenvolvam um espírito científico e crítico, conquistem uma autonomia frente ao conhecimento e, sobretudo, tornem-se educadores que possam assumir sua parcela de responsabilidade pelo tipo de mundo e de sociedade que projetam e, então, saber prospectar ações condizentes a uma participação e intervenção efetiva (BERBEL, 2011).

Além disso, precisamos pensar que a Formação Inicial é um espaço para que o aluno crie um repertório teórico de possibilidades pedagógicas que poderá desenvolver quando atuar em sua própria sala de aula. Ou seja, quanto mais alternativas de atuação pedagógica o professor tiver experimentado/desenvolvido durante a sua formação inicial, melhores condições pessoais e profissionais disporá para atuar com seus alunos e no conjunto das atividades escolares (BERBEL, 2011).

Uma só forma de trabalho pode não atingir a todos os alunos na conquista de níveis complexos de pensamento e de comprometimento em suas ações, como desejados, ao mesmo tempo e em curto tempo. Essa é a razão da necessidade de se buscar diferentes alternativas que contenham, em sua proposta, as condições de provocar atividades que estimulem o desenvolvimento de diferentes habilidades de pensamento dos alunos e possibilitem ao professor atuar naquelas situações que promovem a autonomia, substituindo, sempre que possível, as situações evidentemente controladoras (BERBEL, 2011). Assim como ocorre com a teoria, uma metodologia, por mais promissora que seja pelas suas características, por si só, não transforma o mundo ou a educação, nem mesmo consegue promover a motivação autônoma dos alunos (BERBEL, 2011).

Cabe ao professor, portanto, organizar-se, para obter o máximo de benefícios das Metodologias Ativas para a formação de seus alunos. Além disso, um desafio interessante é o dos registros dos modos como as experiências docentes e discentes são realizadas com essas metodologias e seus efeitos junto aos alunos, de modo a ampliar as reflexões e as evidências de seus benefícios pedagógicos (BERBEL, 2011).

Souza e Dourado (2015) realizaram um trabalho cujo escopo fora o levantamento bibliográfico referente às caracterizações existentes sobre a ABP. Os 
autores apontam que há descrições consensuais acerca da potencialidade dessa metodologia em promover a aquisição de conhecimentos, o desenvolvimento de habilidades, de competências e atitudes em todo processo de aprendizagem, além de favorecer a aplicação de seus princípios em outros contextos da vida do aluno. Assim, a $\mathrm{ABP}$ apresenta-se como um modelo didático que promove uma aprendizagem integrada e contextualizada (SOUZA; DOURADO, 2015).

Quando o processo de aprendizagem tem início a partir de um problema, a reflexão sobre as situações propostas desencadeia a busca de fatores explicativos e a proposição de solução ou soluções para esse problema. Os conteúdos são identificados e construídos pelo estudante, que precisa reorganizar o material de acordo com o conhecimento prévio que possui - seja de outras disciplinas, seja de senso comum para, então, elaborar caminhos investigativos para descobrir relações, leis ou conceitos que precisará aprender (ZANOTTO, 2003).

Dessa forma, o trabalho com problemas em sala de aula enfatiza o aprender a aprender (BERBEL, 1998). Ele pode ser considerado como o eixo principal do aprendizado teórico de determinado conteúdo e objetiva o aprendizado de conteúdos cognitivos e a integração de disciplinas. "Propõe-se a um trabalho criativo do professor que estará preocupado não só com o "que", mas, essencialmente, com o "por que" e o “como" o estudante aprende" (CYRINO; PEREIRA, 2004, p.783).

A ABP fundamenta suas origens na Teoria da Indagação de John Dewey, filósofo, psicólogo e educador norte-americano, citado como grande precursor do pensamento pedagógico contemporâneo. Para John Dewey, a aprendizagem parte de problemas ou situações cujo objetivo é gerar dúvidas, desequilíbrios ou perturbações intelectuais. A partir deste ponto de vista, a metodologia de ensino enfatizaria a descoberta, a experimentação e a reflexão e os docentes abordariam os conteúdos pragmáticos por meio de problemas ou questionamentos (SOUZA; DOURADO, 2015).

A natureza dos problemas e a forma por meio da qual são construídos e propostos tem como objetivo fazer com que o aluno saiba reconhecer contexto conceitual a partir dos conhecimentos prévios já adquiridos, bem como identificar e traçar objetivos de aprendizagem dos conteúdos necessários para a resolução do problema e que, no entanto, são desconhecidos pelos alunos (BERBEL, 1998).

Para Conrado, El-Hani e Nunes-Neto (2013, p. 214), a ABP pode ser realizada no contexto escolar de acordo com sete passos, a saber: 
1. Identificar o problema: entender a relação do problema com a realidade e esclarecer frases e conceitos confusos ou desconhecidos (leitura atenciosa pela equipe para não restar dúvidas sobre o problema).

2. Definir o problema: descrever exatamente que fenômenos devem ser explicados e entendidos, esclarecendo a situação e o tipo de decisão a tomar (indicação de pontos relevantes pela equipe).

3. Brainstorming: usar conhecimentos prévios e o senso comum para formular explicações e buscar respostas para o problema, sem preocupação com exatidão das informações ou com preconceitos sobre as ideias sugeridas (análise do problema com conhecimentos prévios).

4. Detalhar explicações: construir hipóteses que explicam o problema, de forma coerente e detalhada, levantando as lacunas do conhecimento que precisam ser estudadas (resumo das discussões).

5. Propor temas de aprendizagem autodirigida: definir o que precisa ser estudado, meios/recursos para realizar a investigação e ações para pesquisar o problema (formulação de objetivos de aprendizagem).

6. Busca de informações e estudo individual: estudar conteúdos selecionados para preencher lacunas do conhecimento necessário e relevante (informações em fontes diversificadas e confiáveis).

7. Avaliação: compartilhar conclusões com o grupo, integrar conhecimentos adquiridos e avaliar o processo de aquisição desses conhecimentos, a organização geral do grupo, e o avanço na resolução do problema.

É importante destacar que, embora esses passos sejam uma orientação metodológica para o desenvolvimento de atividades que envolvam a ABP, a construção e execução da atividade pode engendrar passos não previstos, o que não deve descaracterizar a efetividade da metodologia.

O papel do professor é fulcral em metodologias como a descrita já que ele conduzirá a investigação e o caminho de resolução do problema. Dessa forma, ele deverá ter propriedade para limitar o "brainstorming" delineando caminhos para que os alunos alcancem, gradativamente, um plano de resolução que irá fornecer uma resposta ao problema. Para tanto, o problema deve ter relação com os conhecimentos prévios dos alunos, de maneira que eles possam reconhecer quais são as lacunas conceituais existentes para que o problema possa ser resolvido como um todo. 
O caminho de entendimento dessas lacunas deve ser determinado pela organização e planejamento do grupo para estudos individuais que serão compartilhados em momento posterior. Essa troca de ideias durante a formulação de hipóteses e estruturação de planejamento pode favorecer muito a aprendizagem cooperativa e coletiva sem, no entanto, desprestigiar o momento de estudo e/ou aprendizagem individual, já que cada um do grupo ficará responsável por suprir determinada lacuna conceitual.

Um dos desafios de realizar esse tipo de trabalho em salas de aula de Ensino Médio é a elaboração e proposição de problemas, dada a sua complexidade. Para a construção de um bom problema, é importante que seja dado um título que chame a atenção do aluno e que, de imediato, identifique o tema objeto de estudo. Este pode ser apresentado em diversos formatos; por exemplo: pequenos vídeos, diálogos impressos, reportagens jornalísticas, figuras, texto impresso, banda desenhada, entre outros (BARELL, 2007; BARRETT; MOORE, 2011).

Há uma diversidade de recursos que podem ser utilizados para constituir o problema. No entanto, é necessário que esse problema atraia o interesse dos alunos, estimulando a pesquisa e a vontade de aprofundar os conteúdos envolvidos; que haja correspondência entre os conteúdos envolvidos na resolução do problema e os objetivos de aprendizagem (o que você quer que o seu aluno aprenda), o contexto ou enunciado tem de ser facilmente apreendido por meio de leitura escrita (com um vocabulário acessível e bem construído); visual (com imagens de boa qualidade e tamanho); auditiva (o som deve ser limpo, sem ruídos permitindo uma boa audição para a compreensão dos alunos). Além disso, deve conter as informações necessárias e relevantes para despertar a curiosidade do aluno e ativar seu conhecimento prévio; não deve conter elementos que distraiam a atenção do tema principal da investigação; deve ser desafiante e trazer os conhecimentos necessários à formulação dos argumentos conceituais que levarão à resolução dos problemas (BARELL, 2007; BARRETT \& MOORE, 2011).

Por exemplo, as questões sociocientífcas e os temas transversais propostos nos Parâmetros Curriculares Nacionais (Ética, Meio Ambiente, Saúde, Pluralidade Cultural, Orientação Sexual, Temas Locais) são temas bastante adequados para o trabalho com aprendizagem baseada em problemas.

Essas questões sócio-científicas (QSCs) são apontadas pelo caráter controverso e polêmico, uma vez que fomentam indagações relacionadas a conhecimentos científicos da atualidade e que, portanto, em termos gerais, são abordados nos meios de 
comunicação de massa (rádio, TV, jornal e internet). Essas problemáticas estão ligadas diretamente à vida das pessoas e mostram-se entre a interface de interesses políticos, econômicos e sociais. Questões como a clonagem, a manipulação de células-tronco, os transgênicos, o uso de biocombustíveis, a fertilização in vitro, os efeitos adversos da utilização da telecomunicação, a manipulação do genoma de seres vivos, o uso de produtos químicos, entre outras, envolvem consideráveis implicações científicas, tecnológicas, políticas e ambientais que podem ser trabalhadas em aulas de ciências com o intuito de favorecer a participação ativa dos estudantes em discussões escolares que enriqueçam seu crescimento pessoal e social (PEREZ; CARVALHO, 2012).

Na educação científica, as estratégias de ensino usadas na ABP podem contribuir para tomada de decisões e formação para cidadania. A elaboração do caso pode considerar os problemas socioambientais reais com os quais se defrontam cotidianamente os cidadãos ou profissionais de certa área. Ou seja, o caso bem construído é uma boa simulação da vida do cidadão, que permite, portanto, uma boa preparação para esta. Nesse caso, o estudante terá condições (conteúdos conceituais, procedimentais e atitudinais) para atuar sobre esses problemas, em suas ações. Isso se opõe às simulações presentes no ensino tradicional de ciências que, quando estão presentes, não são contextualizadas na realidade do estudante (CONRADO; NUNESNETO; EL-HANI, 2014).

$\mathrm{O}$ uso de casos sobre questões socioambientais que estimulam a tomada de decisão e a discussão de suas razões possibilita, além da mobilização de diferentes conteúdos (sejam ou não do mesmo tipo), uma reflexão sobre as próprias ações do estudante no cotidiano como ator social e as consequências dessas ações em diferentes escalas temporais e espaciais para a qualidade de vida social e ambiental (BEARZI, 2009).

Isto posto, procura-se contribuir, no âmbito prático, com possibilidades que acrescentem ideia de trabalho pedagógico na formação inicial de professores de Ciências a partir da resolução de problemas. Para tanto, elaboramos dois problemas para serem trabalhados na Formação Inicial de professores de Ciências para o trabalho com a Educação Ambiental. Os problemas serão apresentados:

\section{PROBLEMA 1}

Um grupo de ativistas está desenvolvendo um projeto de preservação da Amazônia e, para tanto, estão distribuindo um panfleto com o seguinte conteúdo: 


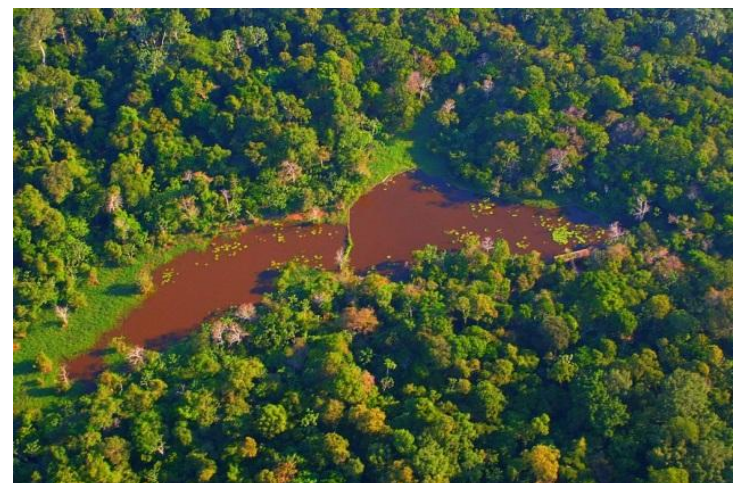

Figura 1. Vista aérea da Floresta Amazônica. Disponível em: < By James Martins, CC BY 3.0, https://commons. wikimedia.org/w/index.php?curid=56472301> Acesso em 10 de setembro de 2017.

"Esta figura representa a importância da Amazônia na vida de cada um de nós. A floresta é considerada o "pulmão do mundo" e, portanto, preservá-la é uma questão fundamental para mantermos o nosso bem-estar e qualidade de vida. Se a floresta continuar sendo desmatada, não teremos $\mathrm{O}_{2}$ suficiente para respirarmos. Pense nisso e preserve!"

Você é dono de uma empresa de grande influência no país, voltada para sustentabilidade, e essa equipe de ativistas quer seu apoio para divulgar o projeto por meio da distribuição desses panfletos. Quando o autor do panfleto diz "preservá-la é uma questão fundamental para mantermos o nosso bem-estar e qualidade de vida", que outras preocupações com a conservação da biodiversidade foram marginalizadas? Que outras consequências podem decorrer do desmatamento da Amazônia além da diminuição de $\mathrm{O}_{2}$ ? É correto chamar a Floresta Amazônica de "pulmão do mundo"? Você concordaria em distribuí-los? Por quê? Que outros problemas conceituais a leitura dos panfletos pode ocasionar? Caso você pudesse sugerir uma alteração no panfleto, como você faria?

\section{PROBLEMA 2}

Você é professor de uma escola que adota material apostilado, altamente sistematizado que tem como principal objetivo apresentar conteúdos específicos para o vestibular. No entanto, em uma reunião, você é surpreendido por pais que questionam a falta de uma formação integrada que permita seus filhos discutir assuntos "midiáticos" e “sociais". Um dos pais menciona, especificamente, a falta de habilidade do filho em entender e argumentar sobre assuntos ambientais, tão frequentemente mencionados em diversos âmbitos de divulgação (por exemplo, questões relacionadas à sustentabilidade, aos transgênicos, ao efeito estufa e respectivas consequências).

Após essa colocação dos pais, você decide marcar uma próxima reunião e apresentar uma nova proposta didático-pedagógica. No entanto, você não poderá alterar 
o programa curricular vigente ou o sistema apostilado (uma vez que os pais também argumentam sobre a necessidade dos filhos serem aprovados em bons vestibulares). $\mathrm{O}$ que você planejaria para a nova proposta didático-pedagógica?

Os problemas apresentados para o trabalho com a EA na Formação Inicial de professores de Ciências envolvem diferentes conteúdos pertencentes a área, além de possibilitar que o aluno construa respostas com base em pesquisas específicas, o que possibilita a construção e apresentação de respostas diferentes, que podem ser dialogadas e discutidas com o professor e com os diferentes grupos. O professor deve trabalhar os problemas de acordo com os passos metodológicos descritos na aprendizagem baseada em problema, tendo em vista a atuação como mediador e incentivador do envolvimento do aluno com o problema. O principal objetivo é que a partir dos problemas apresentados, o professor possa ter novas ideias e propostas para serem trabalhadas em sala de aula.

A apresentação de problemas cuja solução envolve a tomada de decisão dos alunos favorece o trabalho com procedimentos, conceitos e atitudes, uma vez que o grupo de alunos precisa criar planos e projetos a partir dos conceitos que circunscrevem o problema. Por exemplo, no Problema 1, espera-se que o aluno possa apontar caminhos pedagógicos que permitam a integração de conceitos biológicos com EA, por meio da indicação de consequências para além dos interesses antropocêntricos de conservação da floresta somente para preservar a qualidade de vida humana.

Já no Problema 2, deverá pensar a Educação Ambiental como uma proposta para ser trabalhada na escola básica: Quais estratégias? Como a escola pode trabalhar os temas ambientais atuais? O que poderá favorecer a articulação entre os conceitos específicos da EA e os conhecimentos pedagógicos?

\section{CONSIDERAÇÕES FINAIS}

O uso da aprendizagem baseada em problema para o trabalho com a Educação Ambiental na Formação Inicial oportuniza uma apropriação contextualizada e efetiva de conceitos, os quais podem se articular com o cotidiano dos estudantes. A leitura e organização de metodologias a partir do referencial supracitado permite, portanto, que a EA seja abordada a partir de problemas e contextos reais, que, muitas vezes, parecem distantes do espaço escolar. 


\section{REFERÊNCIAS}

BARELL, John F. Problem-Based Learning. An Inquiry Approach. Thousand Oaks: Corwin Press, 2007.

BARRETT, Terry; MOORE, Sarah. New Approaches to Problem-Based Learning. Revitalising your practice in higher education. New York: Routledge, 2011.

BERBEL, Neusi Aparecida Navas. Semina: Ciências Sociais e Humanas, Londrina, v. 32, n. 1, p. 25-40, 2011.

BERBEL, Neusi Aparecida Navas. A problematização e a aprendizagem baseada em problemas. Interface comun saúde educ, v. 2, n. 2, p. 139-154, 1998.

CONRADO, Dália Melissa; EL-HANI, Charbel Niño; DE FREITAS NUNES-NETO, Nei. Sobre a ética ambiental na formação do biólogo. Revista Eletrônica do Mestrado em Educação Ambiental, v. 30, n. 1, p. 120-139, 2013.

CONRADO, Dália Melissa; NUNES-NETO, Nei F.; EL-HANI, Charbel N. Aprendizagem baseada em problemas (ABP) na educação científica como estratégia para formação do cidadão socioambientalmente responsável. Revista Brasileira de Pesquisa em Educação em Ciências, v. 14, n. 2, p. 077-087, 2014.

CYRINO, E. G.; TORALLES-PEREIRA, M. L. Trabalhando com estratégias de ensino-aprendizado por descoberta na área da saúde: a problematização e a aprendizagem baseada em problemas. Cad. Saúde Pública, v. 20, n. 3, p. 780-8, 2004.

DELIZOICOV. D.; ANGOTTI, J. A.; PERNAMBUCO, M. M. Ensino de Ciências: Fundamentos métodos. 4 ed. São Paulo: Cortez, 2011.

GUIMARÃES, Mauro. A dimensão ambiental na educação. 10 ed. Campinhas: Papirus, 2010.

KRASILCHIK, Myriam. O professor e o currículo das ciências. Editora Pedagógica e Universitária, 1987.

MORAN, José M. Educação híbrida: Um conceito- chave para a educação, hoje. In: BACICH, Lilian; NETO, Adolfo Tanzi; DE MELLO TREVISANI, Fernando (Orgs). Ensino Híbrido: personalização e tecnologia na educação. Porto Alegre: Penso, p. 27 $-45,2015$.

NICOLLIER, Valerie; VELASCO, Fermin Garcia C. Conhecer A Mata Atlântica na Infância: Uma Contribuição da Teoria das Inteligências Múltiplas para a Educação Ambiental. Investigações em Ensino de Ciências - v. 14, n. 3, p. 421-456, 2009.

PEDRINI, Alexandre de Gusmão, SAITO, Carlos Hiroo (Org.) Paradigmas Metodológicos em Educação Ambiental. Rio de Janeiro: Vozes, 2014.

PÉREZ, Leonardo Fabio Martínez; CARVALHO, Washington Luiz Pacheco de. Contribuições e dificuldades da abordagem de questões sociocientíficas na prática de professores de ciências. Educação e Pesquisa, v. 38, n. 3, p. 727-741, 2012.

RIBEIRO, Job Antonio Garcia; CAVASSAN, Osmar. A adoção da Aprendizagem Cooperativa (AC) como prática pedagógica na Educação Ambiental (EA): 
possibilidades para o ensino e a aprendizagem de conteúdos conceituais, procedimentais e atitudinais. Pesquisa em Educação Ambiental, v. 11, n. 1, p. 19-36, 2016.

RIBEIRO, Job Antonio Garcia; CAVASSAN, Osmar. Os conceitos de ambiente, meio ambiente e natureza no contexto da temática ambiental: definindo significados. Gondola: Ensenanza Aprendizaje de las Ciencias, v. 8, n. 2, p. 61, 2013.

SOUZA, Daniele Cristina de; FIGUEIREDO SALVI, Rosana. A pesquisa em educação ambiental: um panorama sobre sua construção. Ensaio Pesquisa em Educação em Ciências, v. 14, n. 3, 2012.

SOUZA, Samir Cristino de; DOURADO, Luiz. Aprendizagem baseada em problemas (ABP): Um método de aprendizagem inovador para o ensino educativo. HOLOS, v. 5, p. 182-200, 2015.

STIR, John. Restructuring teacher education for sustainability: student involvement through a "strengths model". Journal of Cleaner Production, v. 14, n. 9, p. 830-836, 2006.

VASCONCELLOS, Maura Maria Morita; BERBEL, Neusi Aparecida Navas; DE OLIVEIRA, Cláudia Chueire. Formação de professores: o desafio de integrar estágio com ensino e pesquisa na graduação. Revista Brasileira de Estudos Pedagógicos, v. 90, n. 226, 2009.

ZANOTTO Maria Angélica do Carmo; ROSE, Tânia Maria Santana de. Problematizar a própria realidade: análise de uma experiência de formação contínua. Educação e Pesquisa, v. 29, n.1, p.45-54, 2003. 